\title{
Uma Aplicação Web para Produção de Textos Narrativos com Enredos Alternativos
}

\author{
Carlos Henrique Camilo da Fonseca, Fernando Cesar Balbino
}

Instituto Federal de Educação, Ciência e Tecnologia de Mato Grosso do Sul

Rod. MS-473, km 23, s/n - 79.750-000 - Nova Andradina - MS - Brasil

carlos.fonseca@novaandradina.org, fernando.balbino@ifms.edu.br

\begin{abstract}
Resumo. Este artigo apresenta uma aplicação Web que provê um ambiente para a produção de textos narrativos, na forma de histórias que tenham enredos alternativos, isto é, em que o leitor possa decidir o "caminho a seguir" dentro da história. Espera-se que a aplicação seja uma ferramenta de estímulo para prática da escrita e da leitura em sala de aula, mediado pelo professor, de forma que histórias com enredos alternativos sejam escritas de maneira colaborativa. Na aplicação, os autores podem compartilhar seus textos com outros autores que, por sua vez, podem alterar o desenrolar das histórias. Assim, o leitor escolherá qual final prefere ler. Desse modo, esperase dar mais estímulo à leitura, visto que os textos podem ter vários finais.
\end{abstract}

\section{Cenário de uso}

A interpretação permite a compreensão de um contexto ou discurso e se amplia no entendimento de uma ideia. Trata-se de uma competência imprescindível não só para o mercado de trabalho e para os estudos, mas para a vida. O ser humano, desde o nascimento, aprende a interpretar gestos, olhares, palavras e imagens, e todo esse processo de desenvolvimento é potencializado através da leitura e da escrita, que promovem o acesso a grande parte da cultura humana (MENEZES, 2009). Para que a interpretação de textos escritos ocorra de forma satisfatória, é necessário que esteja atrelada a outros elementos como: prática da leitura, domínio das estruturas linguísticas e compreensão das relações semânticas.

De acordo com Kupper (2015), aproximadamente 35\% da população brasileira é considerada analfabeta funcional, ou seja, não consegue utilizar a leitura e a escrita de forma efetiva na vida cotidiana. Para ele, o problema do analfabetismo no Brasil pode ser atribuído à falta de uma política educacional efetiva, ampla e cuidadosa, o que coloca o país em uma posição negativa em relação a outros países.

Nesse contexto, este projeto tem como objetivo prover uma ferramenta que estimule a prática da leitura e da escrita. Ele oferece um ambiente para a produção de textos narrativos, na forma de histórias que tenham enredos alternativos, isto é, em que o leitor possa decidir o "caminho a seguir" dentro da história. A proposta é inspirada na série "E agora você decide" (NERUN, 2019), em que o leitor, após ler um trecho da história, tinha que decidir o que fazer diante de uma determinada situação; o leitor, então, era direcionado para uma página específica em que encontrava o desenrolar do enredo baseado na sua decisão e assim por diante.

Os textos narrativos são maioritariamente escritos em prosa. Esse tipo de texto é caracterizado por narrar uma história, que segue uma sequência de várias ações reais ou 
imaginárias. Essas ações são contadas por um narrador e a estrutura do texto pode ser dividida em introdução, desenvolvimento e conclusão. A estrutura narrativa apresenta como principais elementos: espaço, tempo, personagem, enredo e narrador (VIEIRA, 2001). O enredo, neste contexto, é o conteúdo do qual esse texto se constrói. Também chamado de trama, possui sempre um núcleo, que é conhecido como conflito. É o conflito que determina o nível de tensão aplicado na narrativa e é no enredo que se desenrolam os acontecimentos que formam o texto. Esses elementos podem ser apresentados, discutidos e exemplificados por professores em sala de aula para que, finalmente, possam ser colocados em prática pelos alunos através da aplicação.

Para um melhor entendimento da dinâmica da aplicação, segue a análise de um caso de uso: o professor começa a escrever uma história e pede para cada aluno continuar com um enredo alternativo diferente, o que exige que o aluno leia e entenda $o$ que foi escrito para poder continuar a história a partir do ponto em que o professor parou. O professor, por sua vez, poderá ler as diferentes versões da história seguindo os enredos alternativos produzidos pelos alunos. Em um segundo momento, os alunos podem continuar um texto que foi produzido por um colega, exigindo deles a releitura do texto escrito pelo professor, a leitura do texto escrito pelo colega e o entendimento do que eles escreveram para poder propor mais um enredo alternativo.

Esse processo pode ser repetido inúmeras vezes, e dentro de cada texto pode existir uma infinidade de outros textos com possíveis caminhos para o desenrolar da história, chamados de enredos alternativos, conforme a nomenclatura adotada para esse projeto. O público alvo são alunos de Língua Portuguesa do Ensino Médio.

\section{Desenvolvimento}

Para a elaboração do projeto conceitual da aplicação, optou-se por iniciar com a prototipação de interfaces gráficas com o usuário, como meio para o levantamento de requisitos através da instrumentalização e facilitação da comunicação entre desenvolvedores e usuários finais (PREECE; ROGERS; SHARP, 2002). Após a prototipação e com base nos requisitos identificados, foi elaborado o Diagrama de Casos de Uso (Figura 1) com a ferramenta Astah Community (ASTAH, 2009).

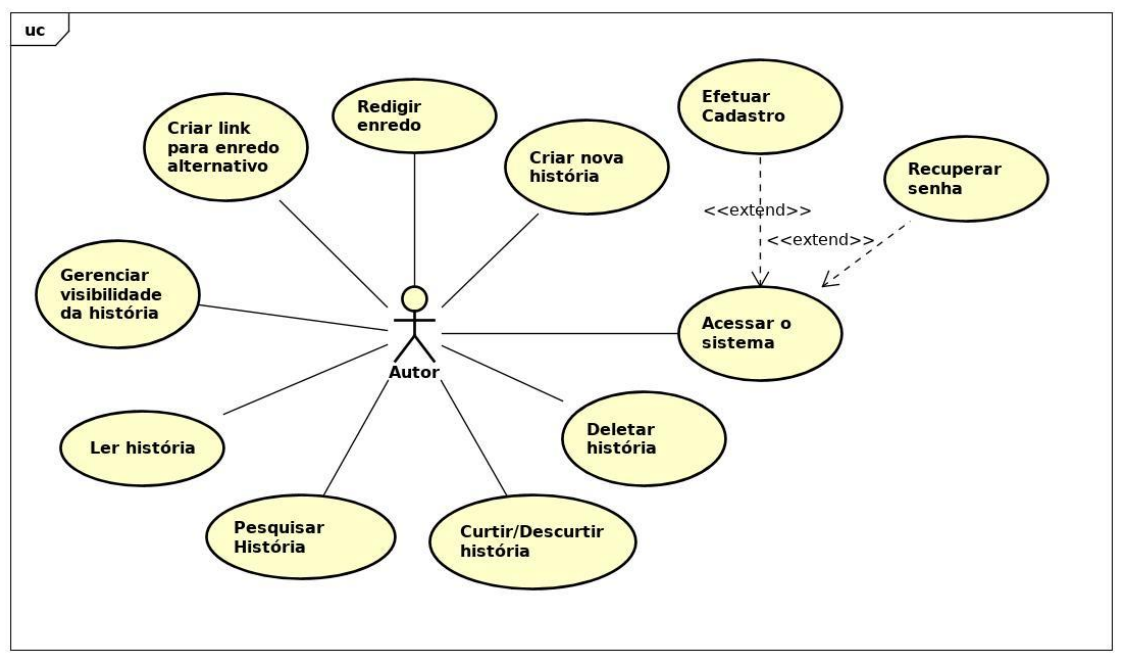

Figura 1. Diagrama de Caso de Uso (Os autores, 2019). 
VIII Congresso Brasileiro de Informática na Educação (CBIE 2019)

Anais dos Workshops do VIII Congresso Brasileiro de Informática na Educação (WCBIE 2019)

O diagrama representativo da estrutura do banco de dados (Figura 2) também foi criado com a ferramenta Astah Community. Nele são exibidos quais dados são armazenados pela aplicação e como eles estão organizados. Para isso, duas coleções foram criadas: a primeira armazena os dados do usuário e a segunda coleção armazena as informações dos textos criados.

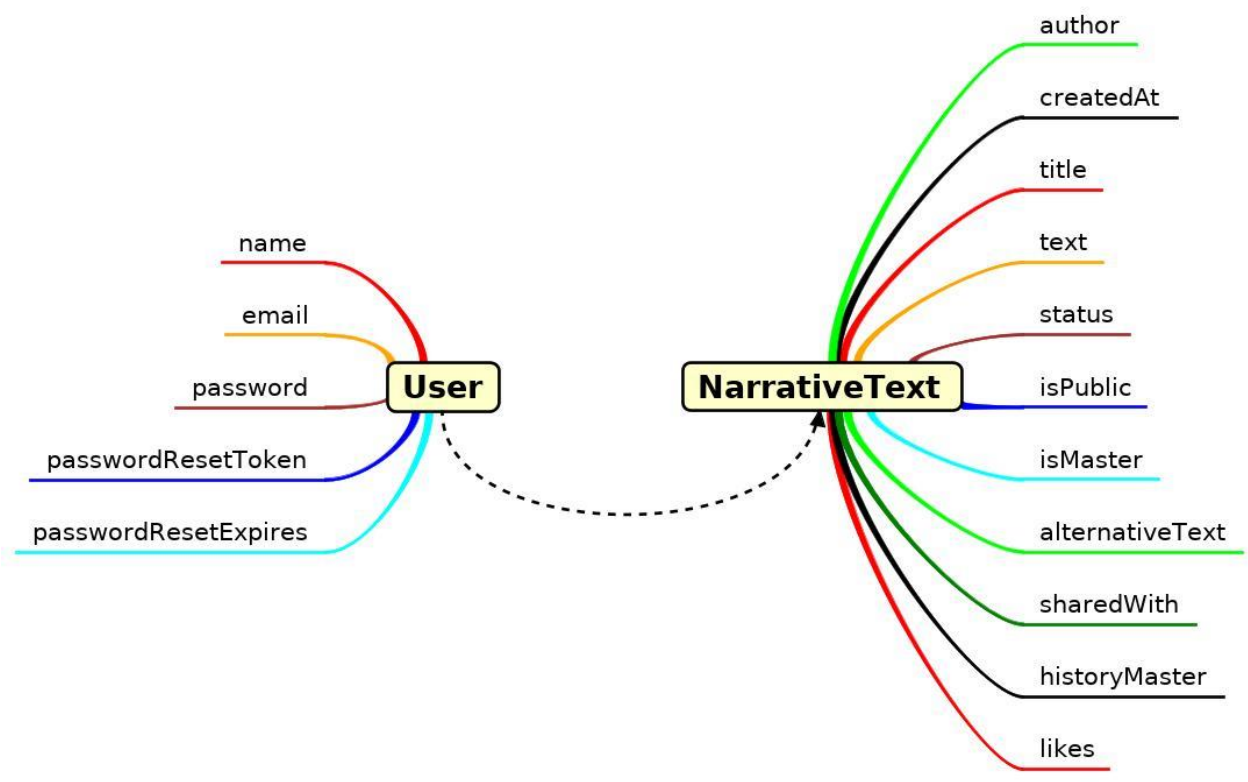

Figura 2. Estrutura do banco de dados não relacional criado com MongoDB (Os autores, 2019).

A aplicação está organizada em duas partes: uma é executada no navegador do usuário (frontend) e a outra em um servidor web (backend).

\subsection{Desenvolvimento do Frontend}

Em uma tradução direta, o termo frontend significa "parte da frente", e dentro do contexto de desenvolvimento Web se refere à parte da aplicação que interage diretamente com o usuário final, ou seja, faz referência à parte visível de um site. $\mathrm{O}$ frontend é composto por todo o código que é executado no lado do cliente, dentro do navegador do usuário. Desse modo, ele vai além das telas, botões, imagens, campos de entrada e formulários, sendo composto também por validações, tratamentos de erros etc.

Para essa implementação foi utilizado o React, uma biblioteca JavaScript de código aberto para criar interfaces de usuário e que é mantido pelo Facebook, Instagram e uma comunidade de desenvolvedores. Optou-se por essa biblioteca, pois com ela é possível criar aplicações com um bom desempenho de atualização de componentes.

Para que seja criado um site com React é necessário usar a Linguagem de Marcação de Hipertexto (HTML), a linguagem de estilização de Folha de Estilo em Cascatas (CSS) e a linguagem de programação JavaScript.

Juntamente com o React, foi também utilizado o Redux, uma biblioteca JavaScript de código aberto que gerencia o estado de uma aplicação. Assim, retira-se o estado dos componentes do React para facilitar a escrita e a manutenção do código desenvolvido. O Redux, que é uma pequena biblioteca com uma API simples e opera 
com o conceito de programação funcional, cria um estado geral para os componentes do React consumirem essas informações.

Juntamente com o Redux foram utilizados os plugins redux-form, redux-multe, redux-promise e redux-thunk, cujos propósitos são facilitar o gerenciamento de formulários, ações múltiplas, Promises e ações assíncronas, respectivamente. $\mathrm{O}$ último plugin utilizado com o Redux foi o react-redux-toastr, que exibe mensagens para o usuário, tanto as que indicam ações bem-sucedidas, como também as de erros.

\subsection{Desenvolvimento do Backend}

Em uma tradução direta, o termo backend significa "parte do fundo". Dentro do contexto de desenvolvimento Web se refere à parte da aplicação que é executada no lado do servidor, ou seja, faz referência à parte não visível de um site. O backend, além de ser composto por todo o código que é executado no lado do servidor, é composto também pelo banco de dados. Desse modo, pode-se garantir a integridade e veracidade dos dados salvos, haja visto que todas as informações do banco devem passar pela validação do servidor.

Para armazenar os dados foi utilizado o MongoDB (2019), conectado a um servidor Node.js. O MongoDB é um banco de dados orientado a documentos, possui código aberto e é classificado como banco de dados NoSQL (2019). Optou-se por esse Sistema Gerenciador de Bancos de Dados (SGBD) porque ele modela informações de modo mais natural e fácil de buscar e, portanto, era adequado para o propósito da aplicação desenvolvida. $\mathrm{Na}$ base de dados criada existem duas coleções: a primeira armazena os dados do usuário e a segunda os textos produzidos, nomeadas de User e NarrativeText, respectivamente, cujas representações são ilustradas na Figura 2.

Apenas o servidor possui autorização para acessar e alterar esses dados. $\mathrm{O}$ servidor foi desenvolvido com o NodeJS, um interpretador de código JavaScript, com código aberto, de modo assíncrono e orientado a eventos, focado em migrar a programação do Javascript do lado do cliente para os servidores. Com ele é possível criar aplicações de alta escalabilidade, capazes de manipular milhares de requisições simultâneas em tempo real, numa única máquina física.

Dentro do servidor NodeJS, foi utilizado o Express, um software livre e de código aberto, projetado para construir aplicativos para Web e APIs. É conhecido como o framework backend padrão para o NodeJS. Ele foi escolhido para esse projeto pois cria abstrações de rotas, middlewares e muitas outras funções para facilitar a criação de uma API.

Dentro do servidor foram criadas duas APIs - openApi e protectedApi, uma aberta e outra protegida, respectivamente. Dentro de openApi foram criadas cinco rotas, a primeira, "/login", para autenticação do usuário; a segunda, "/signup", para a criação de uma nova conta; a terceira, "/validateToken", para validar o token do usuário; a quarta, "/forgotPassword", para quando o usuário esquecer a senha e; a quinta rota, "/resetPassword", para resetar a senha do usuário. Caso o usuário esqueça sua senha de acesso é possível recuperá-la - para isso, ele deve informar seu e-mail e a aplicação enviará para ele um token com validade de uma hora; se o usuário não realizar a alteração dentro do prazo de validade será necessário solicitar um novo token para completar a ação. 
VIII Congresso Brasileiro de Informática na Educação (CBIE 2019)

Anais dos Workshops do VIII Congresso Brasileiro de Informática na Educação (WCBIE 2019)

Para acessar a API protegida, é necessário possuir um token fornecido pela API aberta; sem ele não é possível invocar os métodos do servidor, tornando assim a aplicação mais segura. Na API protegida existem nove rotas que podem ser chamadas a partir de ações do usuário e cada uma faz referência a uma funcionalidade específica:

- $\quad$ index - Rota de paginação, em que são retornadas todas as histórias de um determinado autor.

- $\quad$ indexPublic - Rota de paginação, em que são retornadas todas as histórias públicas e primárias.

- $\quad$ indexHistory - Rota do tipo GET, que retorna uma história.

- $\quad$ addAlternativeText - Rota do tipo POST, que cria uma nova história.

- $\quad$ searchHistory - Rota de paginação, em que são retornadas todas as histórias públicas e todas do autor com o título pesquisado.

- $\quad$ putHistory - Rota do tipo PUT, que altera uma história.

- $\quad$ addLike - Rota do tipo PUT, que adiciona uma curtida para a história.

- $\quad$ removeLike - Rota do tipo PUT, que remove uma curtida da história.

- deleteHistory - Rota do tipo DELETE, que exclui uma história, se a ação for solicitada pelo autor e se ela não tiver nenhum enredo alternativo.

Para gerar mais segurança ao sistema, as senhas do usuário são salvas criptografadas e cada token possui a validade de 24 horas; após esse período é necessário realizar novamente a autenticação.

A conexão do servidor NodeJS com o banco de dados MongoDB é realizada através da biblioteca do Mongoose. Ela é responsável por modelar os dados baseados no esquema das coleções, ou seja, os modelos User e NarrativeText, já mencionados. Com ela são feitas as conversões, validações e consultas da aplicação.

\subsection{Testes de Validação}

Durante todo o processo de construção da aplicação foram efetuados testes para verificar a corretude das funcionalidades implementadas. Quando a aplicação foi concluída, testes de validação foram realizados com alguns usuários - incluindo os autores deste artigo - para experimentar e observar o comportamento da aplicação com simulações de uso real. As primeiras validações formais da ferramenta estão previstas para o segundo semestre letivo do ano corrente, com professores e alunos das disciplinas de Língua Portuguesa do Ensino Médio do Instituto Federal de Mato Grosso do Sul, campus Nova Andradina.

\section{Apresentação do Software}

A aplicação está disponível em https://narrativetext.herokuapp.com/. Quando acessada, caso o usuário não esteja autenticado, é exibido o formulário de autenticação (Figura 3a); caso o usuário não tenha uma conta, é exibido um formulário de cadastro (Figura 3b). Se o usuário já estiver autenticado, é exibida a tela inicial com as histórias públicas, ou seja, as histórias com acesso liberado para leitura (Figura 4). 
VIII Congresso Brasileiro de Informática na Educação (CBIE 2019)

Anais dos Workshops do VIII Congresso Brasileiro de Informática na Educação (WCBIE 2019)

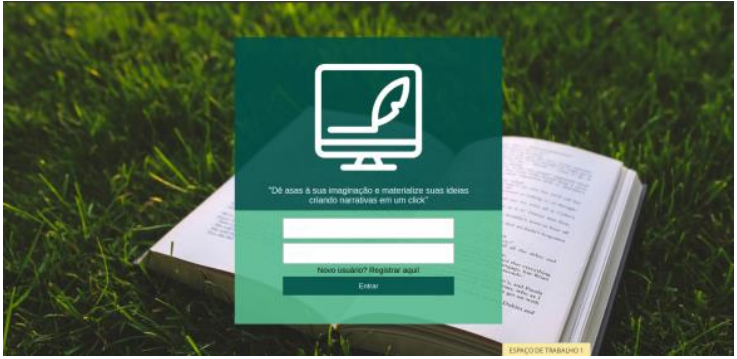

(a)

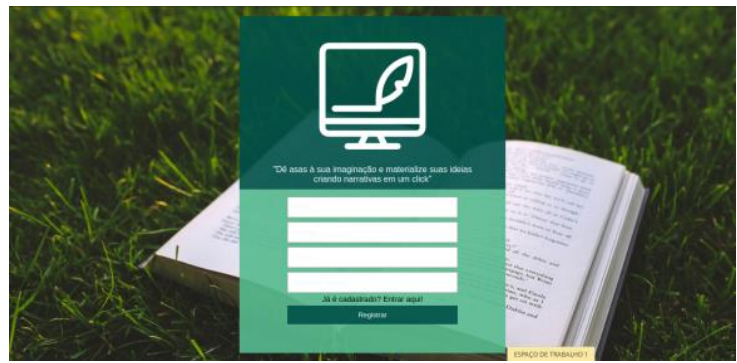

(b)

Figura 3. Telas de autenticação (a) e de cadastro (b) (Os autores, 2019).

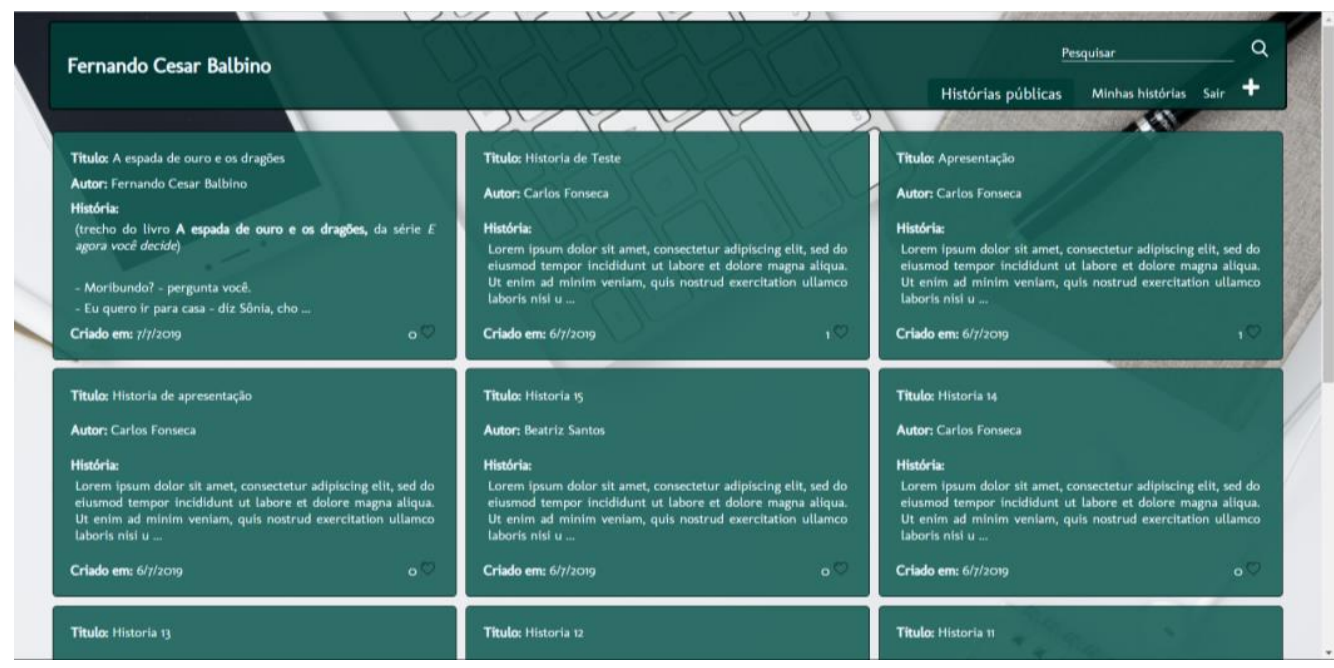

Figura 4. Tela inicial com listagem das histórias com acesso público (Os autores, 2019).

Ao clicar sobre uma das histórias listadas, o usuário é direcionado para a tela de leitura, conforme ilustrada na Figura 5, em que é possível ler, "curtir" (ícone coração) e adicionar um novo enredo alternativo (ícone + ). Caso o usuário autenticado seja o autor da história selecionada, também é exibida a opção para alterá-la (ícone lápis); se a história não tiver nenhum enredo alternativo, é exibida também uma opção para excluíla (ícone lixeira, que não aparece na Figura 5 porque a história já possui enredos).

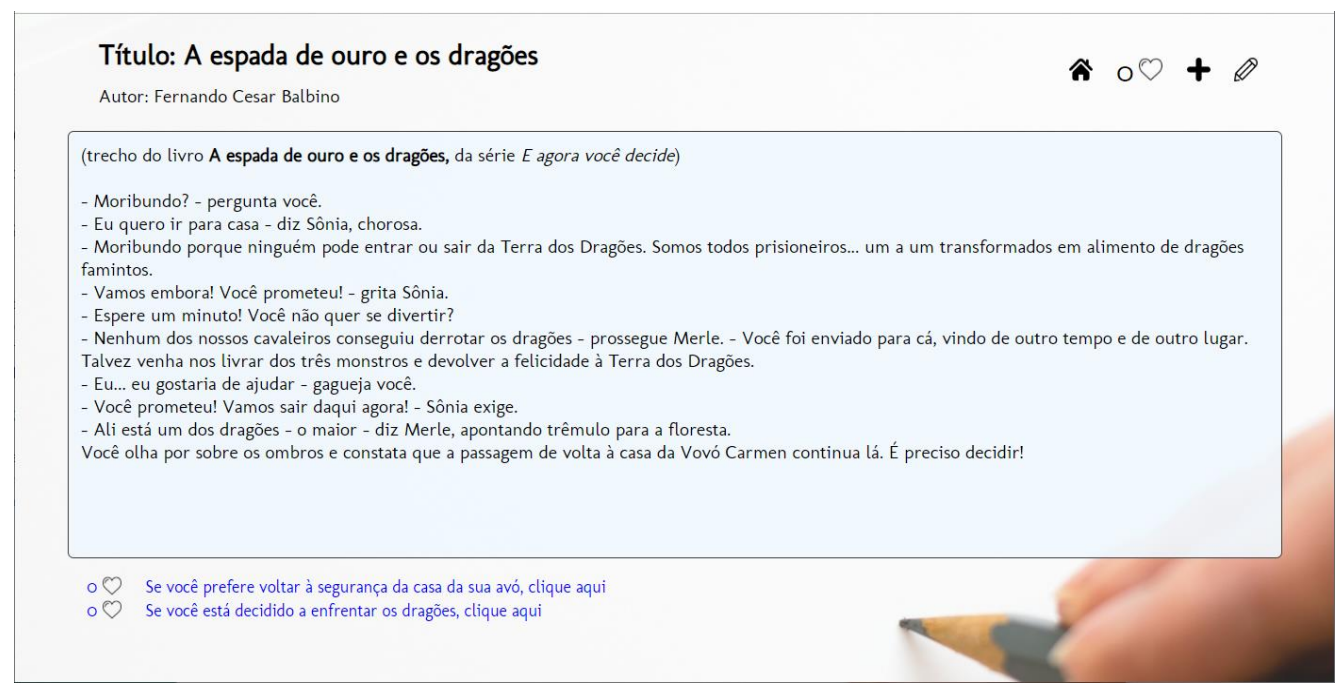

Figura 5. Tela para leitura da história (Os autores, 2019). 
VIII Congresso Brasileiro de Informática na Educação (CBIE 2019)

Anais dos Workshops do VIII Congresso Brasileiro de Informática na Educação (WCBIE 2019)

A opção de "curtir" tem a finalidade de motivar o autor para a escrita de textos criativos, que sejam interessantes e bem redigidos, de forma que a chance de receberem a aprovação - "curtidas" - dos professores e dos colegas seja maior.

Quando o usuário seleciona a opção para criação de uma nova história ou enredo alternativo, ou quando seleciona a opção para edição de um texto previamente salvo, é exibida uma tela conforme ilustrada na Figura 6. Na figura, é possível notar a barra de ferramentas que permite a formatação do texto - como alterar cor, tamanho, espaçamento, fonte, alinhamento etc. -, ampliando as possibilidades do autor da narração quanto a destaques que eventualmente queira fazer no texto em elaboração.

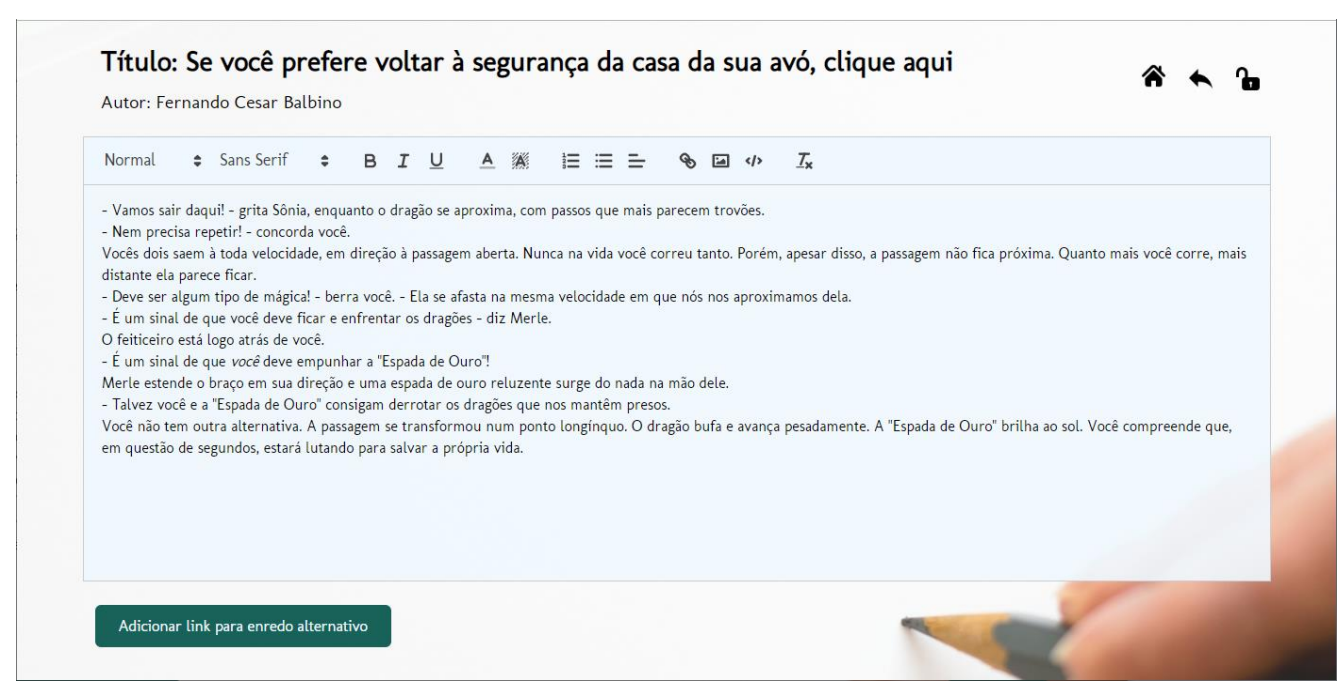

Figura 6. Tela para edição de um texto narrativo (Os autores, 2019).

A opção para criação de uma nova história (ícone + ) é exibida na tela inicial da aplicação (Figura 4); essa opção exibe a tela ilustrada na Figura 7a, em que o autor pode digitar o título da história a ser criada. A opção para criação de um novo enredo alternativo, para uma história em construção, é exibida na tela de edição como um botão (Figura 6) ou, ainda, na tela de leitura (Figura 5), como um ícone (+); ao selecionar uma dessas opções, a aplicação exibe a tela ilustrada na Figura $7 \mathrm{~b}$, em que o autor pode digitar o texto que servirá como título e orientação para o leitor decidir o caminho que deseja seguir na história, conforme os exemplos apresentados na Figura 5.

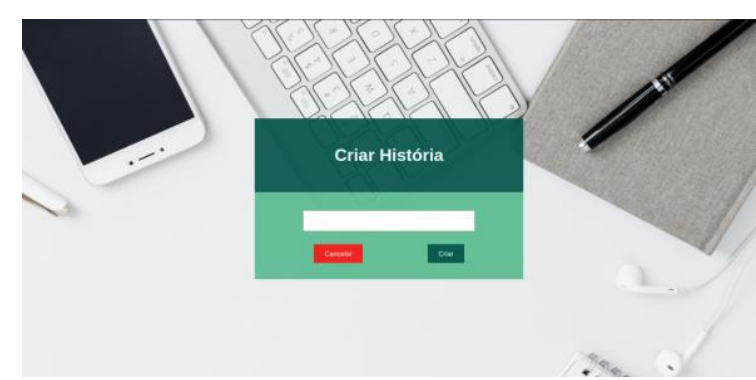

(a)

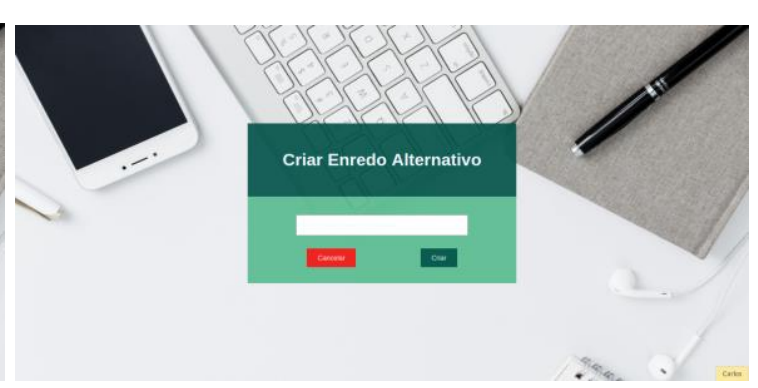

(b)

Figura 7. Telas para criar nova história (a) ou novo enredo alternativo (b) (Os autores, 2019).

Em ambos os casos, a aplicação exibe, na sequência, a tela para escrita da narração (Figura 6), com o título digitado para a história ou enredo, o nome do autor e a área de edição, em branco, para a escrita do novo texto, conforme comentado 
VIII Congresso Brasileiro de Informática na Educação (CBIE 2019)

Anais dos Workshops do VIII Congresso Brasileiro de Informática na Educação (WCBIE 2019)

anteriormente. É importante ressaltar que os textos já armazenados no banco de dados podem ser editados a qualquer momento.

Também é possível alterar a visibilidade da história, tornando-a pública ou privada. Se for pública, todos os usuários do sistema poderão lê-la e adicionar enredos alternativos; se for privada, ela aparecerá apenas para o criador da história.

\section{Considerações finais}

A aplicação Web apresentada neste artigo foi produzida para ser usada por professores de Língua Portuguesa do Ensino Médio como ferramenta de auxílio na produção de textos narrativos, em que é possível criar diferentes enredos que permitem diversas alternativas para o "desenrolar" da história.

Inicialmente, essa aplicação foi concebida com a possibilidade de o professor começar uma história e cada aluno dar continuidade com um enredo alternativo diferente, o que exigiria que o aluno lesse o texto escrito pelo professor, entender a que foi escrito e continuar de acordo com sua criatividade. Contudo, posteriormente, percebeu-se a possibilidade de os alunos escolherem uma história escrita por um colega e continuar de acordo com o que ele escreveu, tornando os autores protagonistas diretos das histórias iniciadas e construídas. Em qualquer uma dessas situações, o propósito da aplicação é estimular a leitura e a escrita, através de um ambiente online para a produção criativa de narrativas com enredos alternativos.

Como trabalhos futuros, pretende-se, entre outros, disponibilizar a aplicação para uso em sala de aula por professores e alunos, de forma a se obter evidências sobre resultados esperados e obtidos, e implementar a funcionalidade para gerar um arquivo PDF das histórias produzidas para download ou mesmo para impressão, facilitando a leitura da história no modo offline.

\section{Referências}

Astah. Astah Community. Disponível em: <http://astah.net/editions/community>. Acesso em: 07 jul. 2019.

Kupper, A. "Sociologia Pré-Vestibular - Volume Único". São José dos Campos, SP: Editora Poliedro, 2015, pp. 205-242.

Menezes, L.C. “A língua em todas as disciplinas”. Nova Escola, São Paulo, n. 221, abr. 2009.

MongoDB. Disponível em: <https://www.mongodb.com>. Acesso em: 07 jul. 2019.

Nerun. GURPZine Blog. "Enrola \& Desenrola - os antigos livros-jogos da Ediouro". Disponível em: <http://www.gurpzine.com.br/enrola-e-desenrola>. Acesso em: 07 jul. 2019.

NoSQL. "NoSQL Databases Explained". Disponível em: $<$ https://www.mongodb.com/nosql-explained $>$. Acesso em: 07 jul. 2019.

Preece, J., Rogers, Y. e Sharp, H. (2002). "Interaction Design: Beyond HumanComputer Interaction". John Wiley \& Sons, Inc, USA.

Vieira, A. G. "Do conceito de estrutura narrativa à sua crítica". Psicologia: reflexão e crítica, v. 14, n. 3, p. 599-608, 2001. 